\title{
Prognostic Value of Carcinoembryonic Antigen and Vascular Endothelial Growth Factor Tumor Tissue Content in Colorectal Cancer
}

\author{
Patrizia Ferroni $^{a}$ Raffaele Palmirotta ${ }^{a}$ Antonella Spila ${ }^{a}$ Francesca Martini $^{a}$ \\ Vincenzo Formica $^{b} \quad$ Ilaria Portarena ${ }^{b} \quad$ Girolamo Del Monte $^{b} \quad$ Oreste Buonomo $^{c}$ \\ Mario Rosellib Fiorella Guadagni ${ }^{\mathrm{a}}$ \\ a Department of Laboratory Medicine and Advanced Biotechnologies, IRCCS San Raffaele Pisana, \\ ${ }^{b}$ Medical Oncology, Department of Internal Medicine and ${ }^{\mathrm{C}}$ Department of Surgery, University of Rome \\ Tor Vergata, Rome, Italy
}

\section{Key Words}

Colorectal cancer • Vascular endothelial growth factor .

Carcinoembryonic antigen · Relapse-free survival · Overall survival

\begin{abstract}
Aim: This study was designed to assess the prognostic significance of the combined measurement of vascular endothelial growth factor (VEGF) and carcinoembryonic antigen (CEA) tissue content with respect to relapse-free and overall survival of patients with colorectal cancer (CRC). Methods: Quantitative evaluation of VEGF and CEA content was performed on protein extracts obtained from tissue biopsies from 69 CRC patients and 15 healthy donors. Results: VEGF significantly correlated with CEA content of either tumor tissues (rho $=0.55, p<0.0001$ ) or corresponding normal mucosa (rho $=0.34, p<0.005$ ). General regression analyses demonstrated that CEA was an independent predictor of VEGF tissue content either in CRC biopsies (regression coefficient $=0.57, p<0.0001$ ) or normal mucosa (regression coefficient $=0.25, p<0.05$ ). Cox proportional hazards survival analysis showed that tumor tissue content of both VEGF and CEA had an independent prognostic value in predicting both relapse-free (hazards ratio $=5.98, p=0.002$ ) and overall (hazards ratio $=4.73, p=0.007$ ) survival, irrespective of Dukes' stage. Kaplan-Meier analysis demonstrated that an
\end{abstract}

elevated tumor content of both CEA and VEGF had a negative prognostic value in respect to either relapse-free (logrank test: $10.4, p=0.001$ ) or overall survival (log-rank test: 7.33, $p=0.007$ ). Conclusion: Tumor tissue VEGF and CEA content determination might add useful prognostic information in the management of patients with CRC.

Copyright $\odot 2006$ S. Karger AG, Basel

\section{Introduction}

Vascular endothelial growth factor (VEGF) is the predominant angiogenic factor in human cancer and its level of expression in colorectal cancer (CRC) - assessed by a variety of techniques including Northern blotting, immunohistochemistry, enzyme-linked immunoassays and/or reverse transcription polymerase chain reaction - has been shown to correlate with tumor development and progression, metastasis and/or tumor vascularity [1-6]. In particular, it has been suggested that VEGF is upregulated in the progression from nonmalignant to malignant colon cancers [7] and that VEGF does play a role early in tumor development at the stage of adenoma formation [2]. Accordingly, it has been suggested that VEGF might be considered an independent prognostic factor for both relapse-free survival (RFS) and overall survival (OS) in patients with CRC [8-12]. Furthermore,

\section{KARGER}

Fax +41613061234 E-Mail karger@karger.ch www.karger.com
(C) 2006 S. Karger AG, Basel

0030-2414/06/0714-0176\$23.50/0

Accessible online at:

www.karger.com/ocl
Patrizia Ferroni, MD

Department of Laboratory Medicine and Advanced Biotechnologies

IRCCS San Raffaele Pisana, Via della Pisana 235

IT-00163 Rome (Italy)

Tel. +39066613 0425, Fax +39066613 0407, E-Mail patrizia.ferroni@sanraffaele.it 
a significant correlation has recently been reported between preoperative serum VEGF and carcinoembryonic antigen (CEA) levels in colon cancer [12], and it has been suggested that the combination of high serum CEA and high serum VEGF levels measured 6 months postoperatively was significantly associated with poor survival compared to high serum CEA and low serum VEGF [13].

We have recently demonstrated that the quantification of the actual VEGF content on protein extracts from tumor tissues may be of advantage over the determination of circulating VEGF levels [6]. Using a commercially available immunoassay to quantitate VEGF on whole protein extracts obtained from biopsies of histologically confirmed neoplastic tissues and corresponding mucosa, histologically confirmed as 'normal', we demonstrated that tissue VEGF content was higher in CRC tissue biopsies compared to corresponding normal mucosa. Furthermore, tumor VEGF content was associated with clinicopathological variables and had an independent prognostic value in respect to OS [6].

The objectives of the current study were to investigate whether there was any relationship between VEGF and CEA content of tumors and corresponding normal mucosa tissues obtained from patients with primary CRC at the time of surgery, and to assess the prognostic significance of their combined measurement with respect to RFS and OS.

\section{Patients and Methods}

\section{Patients}

Sixty-nine consecutive patients (39 males, 30 females; mean age $62 \pm 11$ years) with histologically diagnosed primary colorectal adenocarcinoma (6 in Dukes' stage A, 37 in stage B, 21 in stage $\mathrm{C}$ and 5 in stage D), treated at the Department of Surgery of the University of Rome Tor Vergata, entered into the study. No patient received neoadjuvant chemotherapy or radiation therapy before surgery. No patient received antiangiogenic agents at any time of the study. Curative surgery was performed in all patients, and simultaneous partial hepatectomy for single liver metastasis was performed in the 5 stage $\mathrm{D}$ patients with no residual metastatic tumor $\left(\mathrm{R}_{0}\right)$. Fifty $(72 \%)$ of 69 patients were considered eligible for adjuvant therapy. In particular, 2 of 12 patients with stage B1 CRC accepted to be included in an adjuvant therapy protocol, whereas 3 of 25 stage B2 patients were not considered eligible due to advanced age or comorbidity. Adjuvant therapy was instituted in all stage $C$ patients $(n=21)$ and first-line chemotherapy was instituted in the 5 stage $\mathrm{D}$ patients. Fifteen healthy donors $(7$ males, 8 females; mean age $56 \pm 10$ years) undergoing endoscopy for screening and surveillance for gastrointestinal cancer served as controls.
Patients were followed from the time of diagnosis of primary tumor for at least 3 years after surgery or until time of recurrence (median follow-up 67.4 months, ranging from 14.6 to 153.1). All patients were generally reviewed at 3-month intervals during the first 2 years after surgery. Thereafter, the interval between visits was increased to 6 or 12 months in parallel with tumor stage. No patient was lost at follow-up. The study was performed under the appropriate institutional ethics approvals and in accordance with the principles embodied in the Declaration of Helsinki. Informed consent was obtained from each participating subject.

\section{Sample Collection and Immunoassay}

Multiple biopsies of histologically confirmed neoplastic tissues and mucosa (peeled from colonic wall approximately $10 \mathrm{~cm}$ distant to the tumor) histologically confirmed as normal were obtained at surgery, immediately frozen in liquid nitrogen and subsequently evaluated for VEGF and tumor marker content. Moreover, tissue biopsies of normal colorectal mucosa were obtained from healthy donors. All samples were shown to contain at least $80 \%$ of colonic mucosa cells. All carcinoma specimens were shown to be free of necrotic areas and to contain at least $50 \%$ malignant cells by histopathology. All specimens designated as normal mucosa from carcinoma patients contained at least $80 \%$ colonic mucosa. The quantitative evaluation of VEGF and tumor marker content in tissue was performed on whole protein extracts obtained from all the biopsies as previously described [6, 14, 15].

Tissue VEGF (R\&D Systems, Minneapolis, Minn., USA) and CEA (Abbott Labs, Chicago, Ill., USA) contents were determined using commercially available immunoassays, according to the manufacturers' instructions. VEGF determination was performed using a quantitative sandwich enzyme immunoassay technique with a monoclonal antibody specific for VEGF as the capture antibody and an enzyme-linked polyclonal antibody as the tracer. The assay recognizes both natural and recombinant human VEGF and does not exhibit cross-reactivity with a series of cytokines and growth factors. Intra- and interassay coefficients of variation are below $10 \%$. The minimum detectable dose is lower than $9.0 \mathrm{pg} / \mathrm{ml}$. Results were calculated from a standard curve using recombinant human VEGF in the range of $31.2-2,000 \mathrm{pg} /$ $\mathrm{ml}$. CEA determination was performed using a two-step chemiluminescent microparticle immunoassay on an ARCHITECT i2000 system (Abbott Labs). The analytical sensitivity of the assay was calculated to be better than $0.5 \mathrm{ng} / \mathrm{ml}$ at the $95 \%$ level of confidence.

All protein extracts obtained from colorectal tissues were initially diluted with extraction buffer to a protein concentration of $1.0 \mathrm{mg} / \mathrm{ml}$. The concentrations of VEGF and CEA in the tumor tissues and normal mucosas are expressed per milligram of protein. Measurements were done in a blinded fashion. All samples were assayed in duplicate and those showing values above the standard curve were serially diluted in protein-extraction buffer, and the test was repeated. The value for each sample was calculated as the mean of at least 2 determinations of 3 different biopsies from the same sample. Variability of VEGF content among the different biopsies ranged between 2 and $15 \%$ when positive. Negative results were confirmed as such in all 3 biopsies.

Statistical Analysis

Unless otherwise specified, data are presented as medians and interquartile ranges. Differences between groups were assessed 
by the Wilcoxon matched pairs test, Mann-Whitney $\mathrm{U}$ test and Kruskal-Wallis test. Univariate and multivariate analyses were performed by Cox's proportional hazards model: the first step was performed by the log-rank test, then the covariates found to be associated were included in Cox's regression model. For each variable the proportional hazard was tested. Clinical and laboratory variables considered in the analysis were: age, sex, site of primary tumor, grading, tumor size, lymph node involvement, VEGF and CEA tissue content. The variables that achieved statistical significance in the univariate analysis were subsequently included in a multivariate analysis using a Cox regression model. Only p values lower than 0.05 were regarded as statistically significant. All calculations were made using computer software packages (Egret, Cytel Software Co., Cambridge, Mass., USA and Statistica, StatSoft Inc., Tulsa, Okla., USA).

\section{Results}

Tissue VEGF and CEA contents of colorectal tissues from carcinoma lesions and corresponding normal mucosa of cancer patients, and from normal mucosa of healthy donors are summarized in table 1 . It is interesting to note that the VEGF $(\mathrm{p}<0.0001)$ and CEA $(\mathrm{p}<0.0001)$ contents of histologically normal mucosa from cancer patients are elevated compared with those of histologically normal mucosa from healthy donors, as previously reported [15]. Univariate correlation analysis showed the presence of a significant correlation between VEGF and CEA contents of colorectal tumor tissues ( $r h o=0.55, \mathrm{p}<$ 0.0001 ), corresponding normal mucosa (rho $=0.34, \mathrm{p}<$ 0.005 ) or normal mucosa of healthy donors ( $r h o=0.53$, $\mathrm{p}<0.05$; fig. 1).

General regression analysis was performed on tissue biopsies from CRC patients by forward stepping, including VEGF tissue content as the dependent variable and age, sex, grading, tumor size, nodal status, Dukes' stage of disease and CEA tissue content as independent variables. The results obtained demonstrated that CEA levels were the only independent predictor of VEGF tissue content either in CRC biopsies (regression coefficient $=0.57$, $\mathrm{p}<0.0001)$ or normal mucosa (regression coefficient $=$ $0.25, \mathrm{p}=0.037$; tables 2, 3).

Longitudinal follow-up was attained in all patients. Fifty-one (74\%) of the 69 patients remained free of disease throughout a median follow-up of 76.3 months (ranging from 40.5 to 153.1), while 18 patients experienced recurrence of disease (4 in stage $B, 11$ in stage $C$, 3 in stage $D$; median follow-up: 37.7 months, ranging from 14.6 to 99.6). No differences were observed in age, sex and histotype or site of primary tumor between patients with and without recurrence.
Table 1. Tissue VEGF and CEA content of colorectal tissues from carcinoma lesions and corresponding normal mucosa of cancer patients, and from normal mucosa of healthy donors

\begin{tabular}{lcc}
\hline & $\begin{array}{l}\text { VEGF } \\
\text { pg/mg of protein }\end{array}$ & $\begin{array}{l}\text { CEA } \\
\text { ng/mg of protein }\end{array}$ \\
\hline $\begin{array}{l}\text { Healthy donors } \\
\quad \text { Normal mucosa }\end{array}$ & $3(2-5)^{*}$ & $69(25-105)^{*}$ \\
CRC patients & & \\
$\quad$ Normal mucosa & $45(22-78)$ & $267(148-434)$ \\
$\quad$ CRC tissues & $141(70-375)$ & $1,130(588-2,520)$ \\
Kruskal-Wallis test & $<0.0001$ & $<0.0001$
\end{tabular}

Data are presented as medians with interquartile ranges in parentheses.

* Mann-Whitney U test: normal mucosa from CRC patients vs. that from healthy donors, $\mathrm{p}<0.0001$.

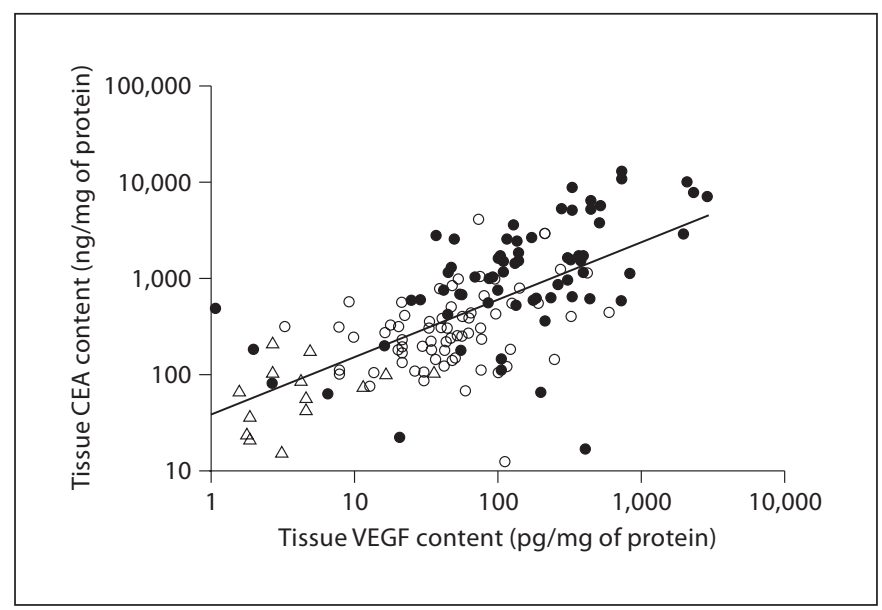

Fig. 1. Correlation analysis of tissue content of VEGF and CEA in tumor biopsies ( $n=69$; closed circles), corresponding normal mucosa ( $n=69$; open circles) and normal mucosa from healthy subjects $(n=15$; open triangles). Spearman rank correlation of all 153 samples: rho $=0.62, \mathrm{p}<0.0001$.

Based on our previously published observations, VEGF and CEA tissue contents were categorized according to previously established cut-off values of $215 \mathrm{pg} / \mathrm{mg}$ of protein [6] and $300 \mathrm{ng} / \mathrm{mg}$ of protein [15], respectively, based on the distribution of the antigen content of colorectal normal mucosa, yielding a specificity greater than $90 \%$. Table 4 reports stage distribution, recurrence and mortality rates within groups of patients categorized on the basis of VEGF and CEA tumor content. As shown, 
Table 2. General regression analysis of VEGF tumor tissue content

\begin{tabular}{|c|c|c|c|c|c|c|}
\hline \multirow[t]{2}{*}{ Predictor variable } & \multicolumn{3}{|c|}{ Univariate analysis } & \multicolumn{3}{|c|}{ Multivariate analysis } \\
\hline & $\beta$-coefficient & $95 \% \mathrm{CI}$ & $\mathrm{p}$ value & $\beta$-coefficient & $95 \% \mathrm{CI}$ & $\mathrm{p}$ value \\
\hline Sex & $0.090(0.114)$ & -0.14 to 0.19 & 0.430 & & & \\
\hline Age & $0.062(0.104)$ & -0.15 to 0.27 & 0.556 & & & \\
\hline Grading & $-0.090(0.118)$ & -0.33 to 0.15 & 0.448 & & & \\
\hline Tumor size & $-0.051(0.122)$ & -0.30 to 0.19 & 0.676 & & & \\
\hline Nodal status & $-0.103(0.232)$ & -0.57 to 0.36 & 0.659 & & & \\
\hline Dukes' stage & $0.252(0.245)$ & -0.24 to 0.74 & 0.307 & & & \\
\hline CEA tumor content & $0.566(0.108)$ & 0.35 to 0.78 & $<0.0001$ & $0.583(0.099)$ & 0.39 to 0.78 & $<0.0001$ \\
\hline
\end{tabular}

Figures in parentheses are SE. CI = Confidence interval.

Table 3. General regression analysis of VEGF normal mucosa content

\begin{tabular}{|c|c|c|c|c|c|c|}
\hline \multirow[t]{2}{*}{ Predictor variable } & \multicolumn{3}{|c|}{ Univariate analysis } & \multicolumn{3}{|c|}{ Multivariate analysis } \\
\hline & $\beta$-coefficient & $95 \% \mathrm{CI}$ & $\mathrm{p}$ value & $\beta$-coefficient & $95 \% \mathrm{CI}$ & $\mathrm{p}$ value \\
\hline Sex & $0.067(0.135)$ & -0.20 to 0.34 & 0.624 & & & \\
\hline Age & $-0.042(0.124)$ & -0.29 to 0.21 & 0.735 & & & \\
\hline Grading & $0.003(0.142)$ & -0.28 to 0.29 & 0.981 & & & \\
\hline Tumor size & $0.106(0.146)$ & -0.19 to 0.40 & 0.472 & & & \\
\hline Nodal status & $0.227(0.279)$ & -0.33 to 0.79 & 0.421 & & & \\
\hline Dukes' stage & $0.181(0.296)$ & -0.77 to 0.41 & 0.542 & & & \\
\hline CEA normal mucosa content & $0.264(0.130)$ & 0.01 to 0.52 & 0.046 & $0.252(0.118)$ & 0.02 to 0.49 & 0.037 \\
\hline
\end{tabular}

Figures in parentheses are SE. CI = Confidence interval.

Table 4. Recurrence rates of patients stratified on the basis of positive/negative values of VEGF or CEA

\begin{tabular}{|c|c|c|c|c|c|}
\hline & Patients, $\mathrm{n}$ & Dukes' stages $^{1}$ & Recurrences, $\mathrm{n}$ & $\begin{array}{l}\text { Type of } \\
\text { recurrence }\end{array}$ & Deaths, $\mathrm{n}$ \\
\hline Negative VEGF and CEA & 9 & $\begin{array}{l}\text { B (8) } \\
\text { C (1) }\end{array}$ & $0(0 \%)$ & & $0(0 \%)$ \\
\hline Positive VEGF or CEA & 34 & $\begin{array}{l}\text { A (5) } \\
\text { B (18) } \\
\text { C (10) } \\
\text { D (1) }\end{array}$ & $5(15 \%)$ & $\begin{array}{l}3 \text { peritoneum } \\
2 \text { liver }\end{array}$ & $5(100 \%)$ \\
\hline Positive VEGF and CEA & 26 & $\begin{array}{l}\text { A (1) } \\
\text { B (11) } \\
\text { C (10) } \\
\text { D (4) }\end{array}$ & $13(50 \%)$ & $\begin{array}{l}3 \text { local } \\
4 \text { peritoneum } \\
5 \text { liver } \\
1 \text { lung }\end{array}$ & $11(85 \%)$ \\
\hline $\mathrm{p}$ value & & & 0.0014 & & 0.0016 \\
\hline
\end{tabular}

${ }^{1}$ Figures in parentheses are numbers of patients. 
Table 5. Cox's proportional hazards analysis of RFS in 69 primary CRC patients, risk set stratification by the variable 'stage of disease'

\begin{tabular}{|c|c|c|c|c|c|c|c|}
\hline \multirow[t]{2}{*}{ Factors } & \multirow[t]{2}{*}{ Code } & \multirow{2}{*}{$\begin{array}{l}\text { Patients } \\
\mathrm{n}\end{array}$} & \multirow{2}{*}{$\begin{array}{l}\text { Recurrences } \\
\mathrm{n}\end{array}$} & \multicolumn{2}{|l|}{ Univariate } & \multicolumn{2}{|l|}{ Multivariate } \\
\hline & & & & $\log$-rank, $\chi^{2}$ & $\mathrm{p}$ value & hazards ratio ${ }^{1}$ & $\mathrm{p}$ value \\
\hline \multirow[t]{2}{*}{ Sex } & female & 30 & $11(37 \%)$ & & & & \\
\hline & male & 39 & $7(18 \%)$ & 5.15 & 0.023 & $4.20(1.34-13.2)$ & 0.014 \\
\hline \multirow[t]{3}{*}{ Site } & colon & 26 & $7(27 \%)$ & & & & \\
\hline & sigma & 19 & $4(21 \%)$ & & & & \\
\hline & rectum & 24 & $7(29 \%)$ & 0.35 & 0.553 & & \\
\hline \multirow[t]{3}{*}{ Grading } & 1 & 18 & $1(7 \%)$ & & & & \\
\hline & 2 & 42 & $14(33 \%)$ & & & & \\
\hline & 3 & 9 & $3(33 \%)$ & 0.53 & 0.466 & & \\
\hline \multirow[t]{2}{*}{ CEA tumor content } & negative & 10 & $0(0 \%)$ & & & & \\
\hline & positive & 59 & $18(31 \%)$ & 2.83 & 0.092 & & \\
\hline \multirow{3}{*}{ VEGF/CEA tumor content } & both negative & 9 & $0(0 \%)$ & & & & \\
\hline & either positive & 34 & $5(15 \%)$ & & & & \\
\hline & both positive & 26 & $11(50 \%)$ & 10.37 & 0.001 & $5.98(1.94-18.5)$ & 0.002 \\
\hline
\end{tabular}

VEGF $>215 \mathrm{pg} / \mathrm{mg}$ of protein was rated positive. CEA $>300 \mathrm{ng} / \mathrm{mg}$ of protein was rated positive.

${ }^{1}$ Figures in parentheses are $95 \%$ confidence intervals.

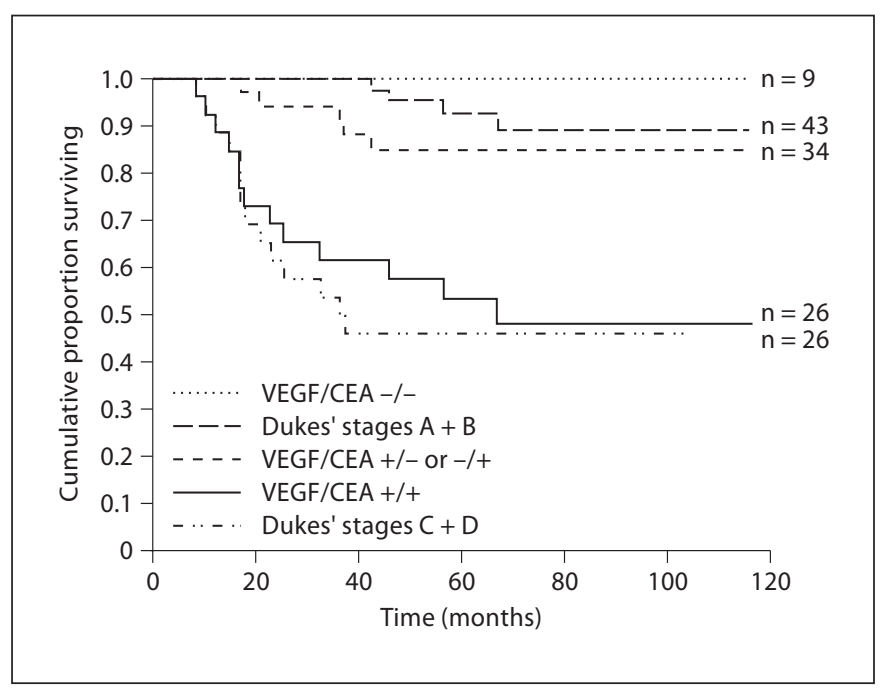

Fig. 2. Kaplan-Meier analysis of RFS time in CRC patients stratified on the basis of VEGF and CEA tumor tissue content (log-rank statistic $=10.4, \mathrm{p}=0.001)$ or stage of disease (log-rank statistic $=$ $4.36, \mathrm{p}<0.0001)$.

9 patients had negative tumor CEA or VEGF content. All of them were alive and free of disease after a median follow-up of 5 years. Five (15\%) of 34 patients with positive VEGF or CEA tumor tissue content had recurrent disease and died after a median follow-up of 3 years. Of the 26 patients with positive tumor tissue content of both variables, $13(50 \%)$ relapsed within a median time of approximately 2 years. Eleven (85\%) died after a median followup of 2.5 years, whereas 2 patients had surgery for a local recurrence or a single liver metastasis and were still alive 6 and 8 years, respectively, after initial diagnosis.

Cox proportional hazards survival analysis was performed after applying a risk set stratification for the variable 'stage of disease' to the model. The results obtained showed that the presence of a positive tumor tissue content of both VEGF and CEA had an independent prognostic value in predicting both RFS (hazards ratio $=5.98$, 95\% confidence interval: $1.94-18.50, \mathrm{p}=0.002)$ and OS (hazards ratio $=4.73,95 \%$ confidence interval: $1.52-$ $14.72, \mathrm{p}=0.007$ ), irrespective of stage of disease (tables $5,6)$.

At a median follow-up of 76.3 months, 14 (20\%) patients had died and $55(80 \%)$ were still alive. Figures 2 and 3 show RFS and OS Kaplan-Meier curves for patients stratified according to VEGF and CEA tumor tissue content (VEGF/CEA -/- vs. VEGF/CEA +/- or -/+ vs. VEGF/CEA +/+) and Dukes' stage. Due to the limited sample size, it was not feasible to break down the survival curves for the evaluation of prognostic impact on VEGF/CEA within each Dukes' stage. Therefore, all subsequent analyses were performed after patients' stratification on Dukes' stages A + B vs. C + D. As shown in 
Table 6. Cox proportional hazards analysis of mortality rates in 69 primary CRC patients, risk set stratification by the variable 'stage of disease'

\begin{tabular}{|c|c|c|c|c|c|c|c|}
\hline \multirow[t]{2}{*}{ Factors } & \multirow[t]{2}{*}{ Code } & \multirow{2}{*}{$\begin{array}{l}\text { Patients } \\
\mathrm{n}\end{array}$} & \multirow{2}{*}{$\begin{array}{l}\text { Deaths } \\
\mathrm{n}\end{array}$} & \multicolumn{2}{|l|}{ Univariate } & \multicolumn{2}{|l|}{ Multivariate } \\
\hline & & & & $\log$-rank, $\chi^{2}$ & $\mathrm{p}$ value & hazards ratio ${ }^{1}$ & $\mathrm{p}$ value \\
\hline \multirow[t]{2}{*}{ Sex } & female & 30 & $9(39 \%)$ & & & & \\
\hline & male & 39 & $5(13 \%)$ & 3.425 & 0.064 & & \\
\hline \multirow{3}{*}{ Site } & colon & 26 & $6(23 \%)$ & & & & \\
\hline & sigma & 19 & $3(16 \%)$ & & & & \\
\hline & rectum & 24 & $5(21 \%)$ & 0.361 & 0.548 & & \\
\hline \multirow[t]{3}{*}{ Grading } & 1 & 18 & $0(0 \%)$ & & & & \\
\hline & 2 & 42 & $11(26 \%)$ & & & & \\
\hline & 3 & 9 & $3(33 \%)$ & 0.804 & 0.370 & & \\
\hline \multirow[t]{2}{*}{ CEA tumor content } & negative & 10 & $0(0 \%)$ & & & & \\
\hline & positive & 59 & $14(24 \%)$ & 2.422 & 0.120 & & \\
\hline \multirow[t]{3}{*}{ VEGF/CEA tumor content } & both negative & 9 & $0(0 \%)$ & & & & \\
\hline & either positive & 34 & $5(15 \%)$ & & & & \\
\hline & both positive & 26 & $13(50 \%)$ & 7.327 & 0.007 & $4.73(1.52-14.7)$ & 0.007 \\
\hline
\end{tabular}

VEGF $>215 \mathrm{pg} / \mathrm{mg}$ of protein was rated positive. CEA $>300 \mathrm{ng} / \mathrm{mg}$ of protein was rated positive.

${ }^{1}$ Figures in parentheses are $95 \%$ confidence intervals.

figure 2, a positive tumor tissue content of both VEGF and CEA had a negative prognostic impact in terms of RFS (5-year RFS 48\%, log-rank statistic $=10.4, \mathrm{p}<0.001$ ). Patients with various stages of CRC and negative VEGF and CEA tumor tissue content had a 5-year RFS rate of $100 \%$, whilst patients stratified according to Dukes' stage displayed a 5-year RFS rate of $93 \%(p=0.417)$ for stages $\mathrm{A}+\mathrm{B}$ and $46 \%(\mathrm{p}=0.007)$ for stages $\mathrm{C}+\mathrm{D}$ (log-rank statistic for stages $\mathrm{A}+\mathrm{B}$ vs. $\mathrm{C}+\mathrm{D}=4.36, \mathrm{p}<0.0001$ ).

Similarly, analysis of OS times showed that positive tumor tissue content of both VEGF and CEA had a negative prognostic value $(5$-year OS 65\%, log-rank statistic = $7.33, p=0.007)$. Patients with various stages of CRC and negative VEGF and CEA tumor tissue content had a 5year OS rate of $100 \%$, whilst patients stratified according to Dukes' stage displayed a 5-year OS rate of 95\% ( $\mathrm{p}=$ $0.496)$ for stages $A+B$ and $65 \%(p<0.05)$ for stages $C+$ $\mathrm{D}$ (log-rank statistic for stages $\mathrm{A}+\mathrm{B}$ vs. $\mathrm{C}+\mathrm{D}=3.21, \mathrm{p}=$ 0.001).

\section{Discussion}

Quantification of the tumor tissue VEGF content in CRC patients has been recommended in a previous study [6]. Here, we report evidences that tumor tissue VEGF and CEA content determination might add useful prog-

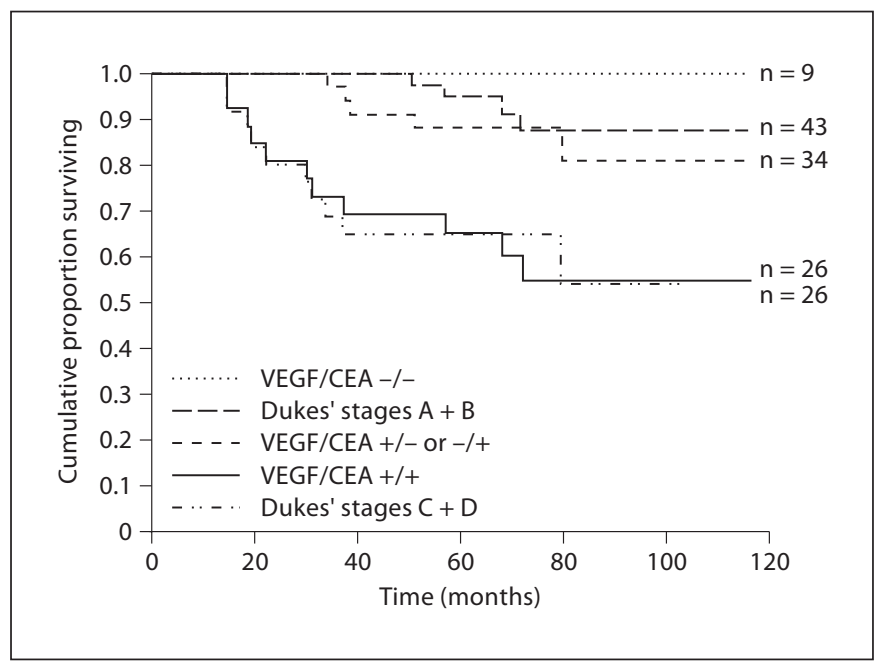

Fig. 3. Kaplan-Meier analysis of OS time in CRC patients stratified on the basis of VEGF and CEA tumor tissue content (log-rank statistic $=7.33, \mathrm{p}=0.007)$ or stage of disease (log-rank statistic $=$ $3.21, \mathrm{p}=0.001)$.

nostic information in the management of patients with CRC. The finding that positive tumor tissue content of both VEGF and CEA had an independent prognostic value in predicting both RFS $(\mathrm{p}=0.002)$ and OS $(\mathrm{p}=0.007)$, irrespectively of stage of disease, provides the rationale 
for the use of novel biological variables in the definition of a subgroup of high-risk patients, which might benefit from stricter follow-up procedures and/or more aggressive treatment. The opportunity to gain prognostic information independently of classic histopathological staging may allow optimizing chemotherapeutic treatment which might not only negatively impact on quality of life and comorbidity, but also correspond to an increase in economic pressure on the national health system. This is particularly true for adjuvant chemotherapy whose use in patients with stage B disease remains controversial because of a lack of level I evidence [16, 17]. In fact, treatment recommendations from the American Society of Clinical Oncology for stage B colon cancer proposed in 2004 that there might be some 'patients with stage B disease that could be considered for adjuvant therapy, including patients with inadequately sampled nodes, T4 lesions, perforation, or poorly differentiated histology'. Similarly, in 2005, the minimum clinical recommendations, issued by the European Society for Medical Oncology, did not advocate the use of chemotherapy in stage B disease, but did state that chemotherapy 'may be considered in selected node-negative patients' [16].

Pilot studies indicated the potential clinical utility of serum VEGF levels in the palliative setting among CRC patients [18, 19]. In contrast, Berglund et al. [20] failed to demonstrate any prognostic and predictive value for VEGF and/or CEA serum levels, which did not provide any relevant clinical information for CRC patients. However, previous studies showed no correlation between CEA content in CRC tissues and serum CEA levels, suggesting that in considering diagnosis or potential therapies (such as anti-CEA recombinant vaccines) serum CEA levels should not be taken as an indicator of CEA expression in tumor lesions [15].

Previous studies demonstrated that colon cancer patients with high level of tissue VEGF expression had an unfavorable outcome compared to patients with VEGFnegative tumors $[5,9,21,22]$, but none of them has evaluated the prognostic value of VEGF in association with CEA tumor tissue content. In our analysis, positive VEGF/CEA patients displayed the worst prognosis both in terms of RFS and OS with 5-year survival rates similar to those of Dukes' stage C $+\mathrm{D}$ patients ( 48 vs. $46 \%$ and 65 vs. $65 \%$, respectively). On the other hand, patients negative for both VEGF and CEA expression demonstrated the most favorable prognosis with 5-year RFS and OS rates of $100 \%$.

Molecular testing of tumor tissues represents the most promising way to identify early stages patients who may need more aggressive approaches. According to our data, stratification of early stages colon cancer patients (Dukes' stages A and B) on the basis of VEGF and CEA tumor content determination can provide a useful tool in discriminating high-risk patients who might benefit from adjuvant treatment.

VEGF is the target of recently developed monoclonal antibodies that have expanded the armamentarium of treatment options for CRC patients. Conceptually, these newer agents are more scientifically appealing than older cytotoxic agents, as they more specifically target unique features of the cancer cells and their surroundings and so attempt to exploit the progress that has been made in the understanding of basic cell biology. The process of new blood vessel development, or angiogenesis, is being investigated for use in CRC patients to reduce growth and metastasis. Bevacizumab (Avastin ${ }^{\mathrm{TM}}$ ), a humanized monoclonal antibody targeting the circulating VEGF, was granted marketing authorization within the EU in January 2005 with the approved indication that 'Avastin (bevacizumab) in combination with intravenous 5-fluorouracil/folinic acid or intravenous 5-fluorouracil/folinic acid/irinotecan is indicated for first-line treatment of patients with metastatic carcinoma of the colon or rectum' [23]. Although the contribution from this drug should not be denied, the therapeutic improvement is still small in absolute terms and comes at a price that will be difficult to handle in tax-funded health care systems [23]. The results obtained in this study suggest that combined measurement of tumor VEGF and CEA content might discriminate patients who can benefit from combination therapies. Trials are ongoing to evaluate the potential use of antiangiogenic drugs in the adjuvant setting (http:// www.clinicaltrial.gov).

Even though response to bevacizumab seems not to be related to the level of VEGF expression in metastatic patients [24], in the adjuvant setting a different biological rationale can be considered. The prognostic impact of high levels of VEGF can be more relevant in the micrometastatic stage of the disease (that is in the adjuvant setting) when the neoangiogenic process is crucial for metastatic development. Similarly, bevacizumab activity can be more accurately predicted by evaluating VEGF tissue expression in this setting. Ongoing adjuvant studies including bevacizumab do not consider VEGF expression in the patient selection process, however, any effort to accurately select patients who really benefit from such expensive therapies is warranted. Thus, the possibility offered by the combined measurement of tumor VEGF and CEA content to identify a subgroup of patients at high 
risk of developing recurrent disease might be of utmost importance in selecting patients with early-stage CRC which may benefit from adjuvant chemotherapy.

VEGF expression has recently been related to clinical response to bevacizumab in tumors other than CRC [25], and it has been suggested that, much as for other therapeutic strategies, apparent resistance to anti-VEGF therapies can occur, probably through hypoxia-triggered upregulation of other proangiogenic factors [26]. Alternatively, genetic polymorphisms might be responsible for different VEGF expression and variability in therapeutic response to bevacizumab. Counteracting such mechanisms of resistance by multitargeting alternative proangiogenic signaling circuits may improve the efficacy of antiangiogenic therapies.

One final issue that raised our attention was the strong correlation between CEA and VEGF content either in tumor biopsies or in normal mucosa. This observation raises another question, namely what causes the increased levels of VEGF and CEA expression in histologically normal mucosa from carcinoma patients versus histologically normal mucosa from healthy donors. Possible reasons are early genetic changes that may predispose a particular individual to develop neoplastic disease during his/her lifetime. Alternatively, increased VEGF or CEA expression might be the result of a paracrine phenomenon in which factors produced by carcinoma cells cause a phenotypic change of adjacent normal colonic mucosa. As the association between CEA and VEGF is concerned, we could hypothesize that CEA might be involved in the regulation of VEGF expression in CRC cancer, as recently demonstrated for other CEA-related cell adhesion molecules, namely CEACAM1 that was found to be one of the major effectors of VEGF in early microvessel formation and angiogenesis $[27,28]$, supporting the growth of invasive tumors [29]. Otherwise, since both CEA and VEGF are overexpressed in the normal mucosa of CRC patients compared to that of healthy subjects, another plausible explanation for the correlation observed might be that both biomarkers could be regulated in an autocrine fashion by factors elaborated by neoplastic tissues in CRC patients.

We are aware that these hypotheses require detailed experimental evaluation before their ultimate significance can be determined. Nevertheless, we hope that our study will prompt investigators to design new studies to better understand the relationship between CEA and VEGF in the disease progression, as well as its contribution as a prognostic factor for CRC. Although our study may be limited by the small sample size, the results reported here strongly suggest that combined measurement of CEA and VEGF tumor tissue content might add useful prognostic information in the management of patients with CRC, and may help in the choice of more aggressive treatment and/or more strict follow-up procedures in a subgroup of patients who are at high risk of recurrence. New prospective studies specifically designed to address this issue are warranted.

\section{References}

-1 Reinmuth N, Parikh AA, Ahmad SA, Liu W, Stoeltzing O, Fan F, Takeda A, Akagi M, Ellis LM: Biology of angiogenesis in tumors of the gastrointestinal tract. Microsc Res Tech 2003;60:199-207.

-2 Hanrahan V, Currie MJ, Gunningham SP, Morrin HR, Scott PA, Robinson BA, Fox SB: The angiogenic switch for vascular endothelial growth factor (VEGF)-A, VEGF-B, VEGF-C, and VEGF-D in the adenoma-carcinoma sequence during colorectal cancer progression. J Pathol 2003;200:183-194.

$\checkmark 3$ Jubb AM, Landon TH, Burwick J, Pham TQ, Frantz GD, Cairns B, Quirke P, Peale FV, Hillan KJ: Quantitative analysis of colorectal tissue microarrays by immunofluorescence and in situ hybridization. J Pathol 2003;200: 577-588.

\footnotetext{
-4 Nakasaki T, Wada H, Shigemori C, Miki C, Gabazza EC, Nobori T, Nakamura S, Shiku $\mathrm{H}$ : Expression of tissue factor and vascular endothelial growth factor is associated with angiogenesis in colorectal cancer. Am J Hematol 2002;69:247-254.

5 Tokunaga T, Oshika Y, Abe Y, Ozeki Y, Sadahiro S, Kijima H, Tsuchida T, Yamazaki H, Ueyama Y, Tamaoki N, Nakamura M: Vascular endothelial growth factor (VEGF) mRNA isoform expression pattern is correlated with liver metastasis and poor prognosis in colon cancer. Br J Cancer 1998;77:9981002.

-6 Ferroni P, Spila A, Martini F, D’Alessandro R, Mariotti S, Del Monte G, Palmirotta R, Buonomo O, Guadagni F, Roselli M: Prognostic value of vascular endothelial growth factor tumor tissue content of colorectal cancer. Oncology 2005;69:145-153.
}

\footnotetext{
7 Wong MP, Cheung N, Yuen ST, Leung SY, Chung LP: Vascular endothelial growth factor is up-regulated in the early pre-malignant stage of colorectal tumour progression. Int J Cancer 1999;81:845-850.

8 Cascinu S, Staccioli MP, Gasparini G, Giordani P, Catalano V, Ghiselli R, Rossi C, Baldelli AM, Graziano F, Saba V, Muretto P, Catalano G: Expression of vascular endothelial growth factor can predict event-free survival in stage II colon cancer. Clin Cancer Res 2000;6:2803-2807.

-9 Galizia G, Lieto E, Ferraraccio F, Orditura M, De Vita F, Castellano P, Imperatore V, Romano C, Ciardiello F, Agostini B, Pignatelli C: Determination of molecular marker expression can predict clinical outcome in colon carcinomas. Clin Cancer Res 2004;10: 3490-3499.
} 
10 Kumar H, Heer K, Lee PW, Duthie GS, MacDonald AW, Greenman J, Kerin MJ, Monson JR: Preoperative serum vascular endothelial growth factor can predict stage in colorectal cancer. Clin Cancer Res 1998;4:1279-1285.

-11 Werther K, Christensen IJ, Nielsen HJ; Danish RANX05 Colorectal Cancer Study Group: Prognostic impact of matched preoperative plasma and serum VEGF in patients with primary colorectal carcinoma. Br J Cancer 2002;86:417-423.

-12 De Vita F, Orditura M, Lieto E, Infusino S, Morgillo F, Martinelli E, Castellano P, Romano C, Ciardiello F, Catalano G, Pignatelli C, Galizia G: Elevated perioperative serum vascular endothelial growth factor levels in patients with colon carcinoma. Cancer 2004; 100:270-278

-13 Werther K, Sorensen S, Christensen IJ, Nielsen HJ; Danish RANX05 Colorectal Cancer Study Group: Circulating vascular endothelial growth factor six months after primary surgery as a prognostic marker in patients with colorectal cancer. Acta Oncol 2003;42:837-845.

14 Guadagni F, Roselli M, Cosimelli M, Spila A, Cavaliere F, Tedesco M, Arcuri R, Abbolito MR, Casale V, Pericoli MN, Vecchione A, Casciani CU, Greiner JW, Schlom J: Correlation between tumor-associated glycoprotein 72 mucin levels in tumor and serum of colorectal patients as measured by the quantitative CA 72-4 immunoassay. Cancer Res 1996;56:5293-5298.

-15 Guadagni F, Roselli M, Cosimelli M, Spila A, Cavaliere F, Arcuri R, D’Alessandro R, Fracasso PL, Casale V, Vecchione A, Casciani CU, Greiner JW, Schlom J: Quantitative analysis of CEA expression in colorectal adenocarcinoma and serum: lack of correlation. Int J Cancer 1997;72:949-954.

-16 Sobrero A: Should adjuvant chemotherapy become standard treatment for patients with stage II colon cancer? For the proposal. Lancet Oncol 2006;7:515-516.
17 Kohne CH: Should adjuvant chemotherapy become standard treatment for patients with stage II colon cancer? Against the proposal. Lancet Oncol 2006;7:516-517.

-18 Takeda A, Shimada H, Imaseki H, Okazumi S, Natsume T, Suzuki T, Ochiai T: Clinical significance of serum vascular endothelial growth factor in colorectal cancer patients: correlation with clinicopathological factors and tumor markers. Oncol Rep 2000;7:333338.

19 Hyodo I, Doi T, Endo H, Hosokawa Y, Nishikawa Y, Tanimizu M, Jinno K, Kotani Y Clinical significance of plasma vascular endothelial growth factor in gastrointestinal cancer. Eur J Cancer 1998;34:2041-2045.

20 Berglund A, Molin D, Larsson A, Einarsson R, Glimelius B: Tumour markers as early predictors of response to chemotherapy in advanced colorectal carcinoma. Ann Oncol 2002;13:1430-1437.

21 Cascinu S, Graziano F, Valentini M, Catalano V, Giordani P, Staccioli MP, Rossi C, Baldelli AM, Grianti C, Muretto P, Catalano G: Vascular endothelial growth factor expression, S-phase fraction and thymidylate synthase quantitation in node-positive colon cancer: relationships with tumor recurrence and resistance to adjuvant chemotherapy. Ann Oncol 2001;12:239-244.

22 Des Guetz G, Uzzan B, Nicolas P, Cucherat M, Morere JF, Benamouzig R, Breau JL, Perret GY: Microvessel density and VEGF expression are prognostic factors in colorectal cancer: meta-analysis of the literature. $\mathrm{Br}$ J Cancer 2006;94:1823-1832.

23 Nygren P, Sørbye H, Österlund P, Pfeiffer P: Targeted drugs in metastatic colorectal cancer with special emphasis on guidelines for the use of bevacizumab and cetuximab: an Acta Oncologica expert report. Acta Oncol 2005;44:203-217.
24 Jubb AM, Hurwitz HI, Bai W, Holmgren EB, Tobin P, Guerrero AS, Kabbinavar F, Holden SN, Novotny WF, Frantz GD, Hillan KJ, Koeppen $\mathrm{H}$ : Impact of vascular endothelial growth factor-A expression, thrombospondin- 2 expression, and microvessel density on the treatment effect of bevacizumab in metastatic colorectal cancer. J Clin Oncol 2006; 24:217-227.

25 Azizi AA, Haberler C, Czech T, Gupper A, Prayer D, Breitschopf H, Acker T, Slave I: Vascular-endothelial-growth-factor(VEGF) expression and possible response to angiogenesis inhibitor bevacizumab in metastatic alveolar soft part sarcoma. Lancet Oncol 2006;7:521-523.

26 Casanovas O, Hicklin DJ, Bergers G, Hanahan D: Drug resistance by evasion of antiangiogenic targeting of VEGF signaling in latestage pancreatic islet tumors. Cancer Cell 2005;8:299-309.

-27 Ergun S, Kilik N, Ziegeler G, Hansen A, Nollau P, Gotze J, Wurmbach JH, Horst A, Weil J, Fernando M, Wagener C: CEA-related cell adhesion molecule 1: a potent angiogenic factor and a major effector of vascular endothelial growth factor. Mol Cell 2000;5:311320.

$>28$ Kilic N, Oliveira-Ferrer L, Wurmbach JH, Loges S, Chalajour F, Neshat Vahid S, Weil J, Fernando M, Ergün S: Pro-angiogenic signaling by the endothelial presence of CEACAM1. J Biol Chem 2005;280:23612369.

-29 Oliveira-Ferrer L, Tilki D, Ziegeler G, Hauschild J, Loges S, Irmak S, Kilic E, Huland H, Friedrich M, Ergün S: Dual role of carcinoembryonic antigen-related cell adhesion molecule 1 in angiogenesis and invasion of human urinary bladder cancer. Cancer Res 2004;64:8932-8938. 